\title{
Orientação de projetos de pra feira de ciências na Escola Estadual Abel Freire Coelho: contribuição para formação dos alunos participantes.
}

\author{
Milton Alexandre Holanda Melo; (Graduando em Química na Universidade do Estado do RN - UERN); \\ Kleviane Batista Gurgel; (Graduando em Química na Universidade do Estado do RN - UERN); \\ Tomaz Guilherme de Sena; (Professor da Escola Estadual Abel Freire Coelho); \\ Antonio Gautier Farias Falconieri; (Professor do DQ na Universidade do Estado do RN - UERN); \\ Email: milton.alexandre@rocketmail.com
}

resumo:

Anualmente as escolas municipais e estaduais da rede básica de ensino promovem as feiras de ciências onde alunos criam projetos, buscando a classificação pra feiras mais importantes podendo levar a conhecer outros países. As feiras de ciências são eventos escolares importantes que incentivam e estimulam estudantes e professores na busca de novos aprendizados, oferecendo-se como espaço importante para a iniciação científica (NEVEZ; GONÇALVEZ, 1989). Assim o presente trabalho tem como objetivo analisar como as feiras de ciências contribuem para a formação profissional e pessoal dos alunos participantes da feira de ciências do décimo segundo Diretoria Regional de Educação (DIRED). Para a produção do projeto foi utilizado uma pesquisa do tipo qualitativa e exploratória, que visa entender o aprendizado dos alunos no âmbito escolar e social e sua relação com a troca de informações com a sociedade. Para isso foi aplicado um instrumento metodológico designado como "balanço do saber" que utiliza a produção de texto, no qual o aluno é avaliado por meio de uma pergunta. A entrevista foi realizada durante uma feira na Escola Estadual Professor Abel Freire Coelho, onde estavam reunidos projetos de várias escolas da rede pública de ensino da $12^{\mathrm{a}}$ DIRED. A discussão busca abordar as contribuições na formação acadêmica, social e pessoal dos alunos participantes. Ao participarem da feira de ciências os alunos do ensino médio tiveram a oportunidade ganhar experiências e um aprendizado diferente daqueles aplicados em sala de aula, o qual irá contribuir para sua formação acadêmica, social e pessoal. Os trabalhos produzidos e o processo de orientação possibilitaram uma troca de experiências que são observadas até mesmo pelos alunos. Com a realização das feiras de ciências é visível que a participação e organização do evento trazem uma grande contribuição que vai além da formação acadêmica, são atributos que influenciam nas relações pessoais com o próximo e no desenvolvimento do estudante durante sua carreira, devido se tratar de um ambiente muito rico, para troca de experiências e conhecimentos. Por isso esses eventos devem ser estimulados ainda mais nas escolas e em conjunto com a comunidade e outras instituições de ensino.

pallavras-chave:

Feira de ciências; Orientação; Formação acadêmica. 


\section{I ntrodução}

O Brasil é um país que possui muitos problemas advindos da educação desde o ensino fundamental ao médio. Essa afirmação é comprovada pelo Índice de Desenvolvimento da Educação Básica (IDEB) e pelo Exame Nacional do Ensino Médio (ENEM) e por dados obtidos pelo órgão que rege a educação no Brasil o Ministério da Educação (MEC). Com a existência dessa problemática o Governo Federal criou o Programa Institucional de Iniciação a Docência (PIBID), que age por meio de universitários de cursos de licenciatura, atuando em escolas públicas do ensino médio, aprimorando sua prática docente e criando novas metodologias de ensino.

O PIBID é um projeto que visa à iniciação à docência dos alunos de licenciatura, no qual atua fornecendo bolsas de incentivo para os discentes produzirem trabalhos e se familiarizar com ambiente escolar. Esse projeto abre portas para que se possam criar metodologias de ensino que possibilite ao aluno do ensino médio aprender, até as disciplinas vista como complicadas, dentre elas a disciplina de química é uma das mais discriminadas.

O PIBID e desenvolvido em todo território nacional em universidades estaduais federais e nos institutos federais (IFs). No estado do Rio Grande do Norte o programa existe em duas universidades a Universidade Federal do Rio Grande do Norte (UFRN), a Universidade do Estado do Rio Grande do Norte (UERN) e Instituto Federal do Rio Grande do Norte (IFRN).

Na Universidade do Estado do Rio Grande do Norte o PIBID trabalha em vários cursos distintos são elas: Ciências Biológicas, Ciências Sociais, Filosofia, Física, Geografia, História, Letras/Espanhol, Letras/Inglês, Letras/Português, Matemática, Música, Pedagogia, Química, Ciência da Religião e Educação Física.

O curso de química contempla três escolas estaduais da cidade de Mossoró nos quais são a Escola Estadual Professor Abel Freire Coelho, Centro de Educação Integrada Professor Eliseu Viana e a Escola Estadual Moreira Dias, os bolsistas trabalham com um único objetivo melhorar a prática docente com uma metodologia inovadora. Nas escolas são divididos grupos de 5 bolsistas e cada grupo tem um supervisor, para acompanhar o andamento dos projetos e orientar os bolsistas quando necessário.

Na Escola Estadual Professor Abel Freire Coelho existe dois grupos atuando pela manhã e outro pelo turno da tarde, todos desenvolvendo projetos na área de ensino.

Com a vivência na escola, os bolsistas participam de eventos realizados na mesma, onde anualmente é promovida uma feira de ciências onde alunos produzem projetos de pesquisa e são apresentados ao público de todas as faixas da sociedade, buscando a classificação pra feiras mais importantes podendo levar a conhecer outros países.

A realização dessas feiras é muito importante para a formação acadêmica dos alunos participantes, onde desenvolvem competências e habilidades diferentes daquelas obtidas exclusivamente em sala de aula como, por exemplo, o método científico ou a capacidade de apresentação em público e explicação para todos os públicos que seja de fácil entendimento.

Com isso esse trabalho irá analisar a contribuição acadêmica e social dos estudantes participantes.

As feiras de ciências são eventos escolares importantes que incentivam e estimulam estudantes e professores na busca de novos aprendizados, oferecendo-se como espaço importante para a iniciação científica (NEVEZ; GONÇALVEZ, 1989). Todavia esses eventos vão mais além de promover aprendizagem dos conhecimentos científicos.

Elas também possibilitam uma mudança de posição do aluno em relação ao conhecimento, para uma postura de um conhecer mais participante, mais ativo (DORNFELD; MALTONI, 2011).

Assim o presente trabalho tem como objetivo analisar como as feiras de ciências contribuem para a formação profissional e pessoal dos alunos participantes da feira de ciências da $12^{\mathrm{a}}$ DIRED.

\section{Metodologia}

Para a produção do projeto foi utilizada uma pesquisa do tipo qualitativa e exploratória, que visa entender o aprendizado dos alunos no âmbito escolar e social e sua relação com a troca de informações com a sociedade. 
Para isso foi aplicado um instrumento metodológico designado como "balanço do saber" que utiliza a produção de texto, no qual o aluno é avaliado por meio de uma pergunta.

O instrumento foi adaptado para atender os propósitos da pesquisa, onde foi realizada uma entrevista com base em uma pergunta buscando avaliar o aprendizado individual de cada aluno participante. A pergunta feita na entrevista foi: O que você aprendeu com a produção do projeto?

A entrevista foi realizada durante uma feira na Escola Estadual Professor Abel Freire Coelho, onde estavam reunidos projetos de várias escolas da rede pública de ensino da $13^{\mathrm{a}}$ DIRED. Os questionários foram distribuídos de forma aleatória de forma que englobasse todas as escolas participantes da feira.

Para a análise dos dados, as respostas foram organizadas em categorias de acordo com a sua similaridade e apoiadas na análise de conteúdo (BARDIN, 2011). Para exemplificar cada categoria foram inseridos no trabalho alguns trechos das respostas dos alunos, onde não foram revelados seus nomes, sendo identificados apenas por uma letra maiúscula.

A discussão busca abordar as contribuições na formação acadêmica, social e pessoal dos alunos participantes.

\section{Resultados e discussão}

Para a realização do trabalho foram entrevistados 20 estudantes, os quais produziram trabalhos publicados na feira, em diferentes escolas. Com a análise de conteúdo dos questionários foram observadas três categorias, as quais podem ser visualizadas no quadro I. (Vale ressaltar que as respostas se encaixam em mais de uma categoria).

Quadro I - Categorias identificadas com base na análise de conteúdo.

\begin{tabular}{|c|c|}
\hline Categoria & Relaciona-se a.. \\
\hline [1] “Conhecimentos específicos do projeto” & $\begin{array}{c}\text { Conhecimentos relatados sobre o conteúdo do } \\
\text { projeto, metodologia científica. }\end{array}$ \\
\hline [2] “Aspecto social” & Respostas que ressaltem a importância social. \\
\hline [3] “Trabalho em equipe e responsabilidade” & $\begin{array}{c}\text { Trabalhar em grupo e a responsabilidade pra } \\
\text { produzir o trabalho. }\end{array}$ \\
\hline
\end{tabular}

Dez entrevistados aprenderam conceitos relacionados a conhecimentos específicos do projeto, quatro ressaltaram que aprenderam a importância do aspecto social que os projetos apresentam e sete pessoas responderam que aprenderam a trabalhar melhor em equipe e expressaram a importância de ter responsabilidade para realizar o projeto.

A primeira categoria [1] "Conhecimentos específicos do projeto", aborda os conhecimentos relacionados especificamente sobre o projeto, onde eleva a capacidade do aluno, pois aprende conteúdos não aplicados em sala de aula. Alguns conhecimentos específicos foram sobre a linguística pragmática, efeito estufa, conhecimento relacionado ao desperdício de água, Aprender os conhecimentos inseridos nos projetos remete a uma relação cognitiva pessoal, mobilizada pelo próprio sujeito. Surge de uma necessidade intrínseca do sujeito para desenvolver atividades novas.

Na maior parte desses conhecimentos se observa o uso de "figuras do aprender de domínio de atividades" (CHARLOT, 2000, p. 66.), como pode ser visto no seguinte trecho escrito:

"Eu aprendi que as palavras estrangeiras nem sempre tem o significado original.” (Aluno F.).

Outra questão proposta na categoria é o aprendizado do método científico, o qual esses projetos necessitam para serem colocados em prática e que tornará possível ser produzido. Isso pode ser verificado através das palavras escritas a seguir:

"Aprendi maiores métodos de formulações de projetos, método científicos e novos conhecimentos" (Aluno A.)

Na segunda categoria [2] "Aspecto social" estão inseridas as respostas que ressaltaram a importância do projeto no meio social, como no trecho escrito abaixo que fala de um problema existente no país que afeta todas as classes sociais que é o desperdício de água:

“Aprendi que a gente tem que ter conhecimento sobre o desperdício de água e evitá-lo.” (Aluno G.). 
Na terceira categoria [3] “Trabalho em equipe e responsabilidade”, os saberes são relacionados e, manifestados por dispositivos relacionais, porém, submergem a relação de saber com o outro a interação mais importante, de acordo com o texto escrito a seguir:

"Aprendi a trabalhar em grupo. Fiquei mais responsável, até porque o meu projeto tem como objetivo de proteger as crianças.” (Aluno C.).

Ao participarem da feira de ciências os alunos do ensino médio tiveram a oportunidade de ganhar experiências e um aprendizado diferente daqueles aplicados em sala de aula, no qual irá contribuir para sua formação acadêmica, social e pessoal. Os trabalhos produzidos e o processo de orientação possibilitaram uma troca de experiências que é observada até mesmo pelos alunos.

Além da troca de experiências, aconteceu também o trabalho em equipe e uma grande contribuição para a formação dos estudantes, fazendo com que os alunos discutissem entre si, aguçassem a criatividade e exercitassem a paciência, compressão e didática.

Outro aprendizado importante e a relevância social abordada pelos estudantes, pois mostram a preocupação com o meio onde vivem e a busca de uma vida melhor.

Em suma todo esse aprendizado é fundamentais na formação pessoal, acadêmica e social dos alunos e muitas dessas habilidades, exercidas na construção do projeto são características de atividades que a graduação requer para, facilitar sua jornada acadêmica e profissional.

\section{Conclusão}

Com a realização das feiras de ciências é visível que a participação e organização do evento trazem uma grande contribuição que vai além da formação acadêmica, são atributos que influenciam nas relações pessoais com o próximo e no desenvolvimento do estudante durante sua carreira, devido se tratar de um ambiente muito rico para troca de experiências e conhecimentos. Por isso esses eventos devem ser estimulados ainda mais nas escolas e em conjunto com a comunidade e outras instituições de ensino.

\section{Guidance for science fair projects in the State School Abel Coelho Freire: contribution to training of the participating students.}

Albstract: Every year the municipal and state schools of teaching basic network promote the science fairs where students create projects, seeking to rank the most important fairs may lead to learning about other countries. The science fair are important school events that encourage and stimulate students and teachers in the search for new learning, volunteering as an important space for scientific research (NEVEZ; Gonçalves, 1989). Thus the present study aims to analyze how the science fair contribute to the professional and personal development of students participating in the science fair of the 12th DIRED. For the production of the project was used a survey of qualitative and exploratory type, which aims to understand student learning in school and social context and its relation to the exchange of information with society. For this was applied a methodological tool called "balance of knowledge" which uses the production of text in which the student and evaluated by means of a question. The interview was conducted during a science fair at the Escola Estadual Professor Abel Freire Coelho, where were gathered projects of various schools of the public school system of the 12th DIRED. The discussion seeks to address the contributions in academic, social and personal formation of the participating students. To participate in the high school science fair, students had the opportunity to gain experience and a different learning from those applied in the classroom, which will contribute to their academic, social and personal formation. The works produced and the orientation process enabled an exchange of experiences that is observed even by students. With the completion of science fairs is apparent that participation and event organization bring a great contribution that goes 
beyond academic education, are attributes that influence personal relationships with others and in student development during his career, because it is a very rich environment, to exchange experiences and knowledge, so these events should be encouraged even more in schools and in conjunction with the community and other educational institutions.

Keywords: Science fair; orientation; Academic education.

\section{Referências bibliográficas}

BARDIN, L. Análise de conteúdo. 2. ed. Lisboa: Edições 70, 2011.

CHARLOT, Bernard. Da relação com o saber: elementos para uma teoria. Porto Alegre: Artmed, 2000.

DORNFELD, C. B.; MALTONI, K. L. A feira de ciências como auxílio para a formação inicial de professores de ciências e biologia. Revista Eletrônica de Educação. São Carlos, SP: UFSCar, v. 5, no. 2, p.42-58, nov. 2011.

NEVES, S. R. G. e Gonçalves, T. V. O. (1989). Feiras de Ciências. Cad. Cat. Ens. Fís., 6 (3), 241-247. 